\title{
Temperature field distribution of a freeze sinking shaft under seepage conditions in cretaceous formation of Western China
}

\author{
Yao Wei, Lei Wang*, Gengshe Yang \\ School of Architecture and Civil Engineering, Xi'an University of Science and Technology, Xi'an 710054, China
}

Corresponding Author Email: wls3016@163.com

https://doi.org/10.18280/ijht.360336

Received: 8 January 2018

Accepted: 10 May 2018

\section{Keywords:}

artificial freezing, temperature field, seepage, closur

\begin{abstract}
This paper attempts to disclose the distribution law of artificial freezing temperature field in Cretaceous sandstone of western China and determine the key parameters of freeze sinking. For this purpose, a numerical model was established in light of the general conditions of freeze sinking project, the model parameters were optimized according to onsite monitored data, and the optimized model was applied to explore the change law of the freezing temperature field. The simulation reveals that the temperature of each measuring point decreased linearly with time, but the mean daily decline differed from point to point: the daily decline is negatively correlated to the distance from the freezing point, i.e. the temperature is positively correlated to the distance from the freezing point at the same time. The freezing time for closure was 79d at the groundwater flow rate of $50 \mathrm{~m} / \mathrm{d}$. When the freezing intensity was weak (freezing tube temperature: $-22^{\circ} \mathrm{C}$ ), the frozen wall failed to achieve closure. This means the groundwater directly bears on the distribution of the temperature field. The freezing intensity has a nonlinear impact on the temperature field. The higher the temperature, the smaller the impact on the closure.
\end{abstract}

\section{INTRODUCTION}

The freeze sinking in thick alluvium of central and eastern China requires a freezing plan with three or four rings, due to the severe frost heaving of the clay stratum. For example, the three-ring and four-ring plans are respectively adopted in Liangbaoshi shaft and Guotun shaft, Juye coalfield, Shangdong Province. By contrast, the freeze sinking in Cretaceous stratum of western China often uses one ring of freezing holes and one ring of auxiliary holes. Typical examples of this combined plan include Mengcun coalmine in Binchang mining area and Wuju coalmine in Gansu Province. However, sing-ring freezing may fail to achieve closure due to groundwater seepage. To solve the problem, Hu Xiangdong [1-2] looked for the analytical solution of temperature field distribution under different freezing conditions, considering the freezing conditions of sing-ring and multi-ring plans. Li Guofeng et al. [3] studied the distribution features of temperature field in three-phase medium. Shi Rongjian et al. [4] explored the variation law of freezing temperature field enhanced by liquid nitrogen. Chen Junhao et al. [5, 6] simulated the temperature field of multi-ring freezing, numerically calculated the temperature field under the deflection of the freezing tube, and analysed the field measurement results using information visualization software for temperature field; Meanwhile, these scholars conducted indoor three-ring freezing model test on the freezing air shafts in Gubei coalmine, aiming to disclose the impacts of different freezing parameters on the development of the frozen wall temperature field. With the aid of vibrating wire sensors, Yang et al. [7] measured the freezing pressure and interface temperature of the bedrock in an air shaft of a coalmine in Gansu Province, and studied the variation law, genesis and unevenness of the Cretaceous bedrock freezing pressure during the drilling period. For the freezing method, the freezing pipe fracture phenomenon caused by the frost heaving stress often occurs. Zong Xiang [8] put forward a construction plan in which the holes in the main ring are frozen before the auxiliary holes in the outer ring, and proved that the plan can successfully prevent the breaking of the freezing pipe caused by the frost-heave stress. Fang Qing [9] simulated the development of the temperature field for the frozen wall in the unexcavated soil layer using the finite-element software ANSYS. Targeting the freeze sinking of an inclined shaft in northern Shaanxi Province, Ren Jianxi et al. [10] explored the law and cause of the freezing pressure variation during freezing and thawing, and compared the measured and simulated results of the radial temperature of the temperature measuring hole and the frozen wall. Sheng Tianbao et al. [11] measured the temperature field of multi-ring frozen wall in the freezing shaft of Zhaogu coalmine 1\#, and solved such problems in the early phase of freeze sinking as the wall caving in the shallow section, the freezing of the deep section, the waste of cooling capacity, and the slow boring speed [12-13].

Overall, the above studies enrich the research on artificial freezing, but fail to tackle the soft rock freezing under complex conditions. To make up for the gap, this paper establishes a numerical model on the distribution law of temperature field of a freeze sinking project in Mengcun coalmine, western China, and determines the key freezing parameters through the analysis on the variation laws of freezing temperature under different conditions. 
2 SITE MONITORING AND ANALYSIS OF FREEZE SINKING

\subsection{Intelligent monitoring system}

The three-layer intelligent monitoring system mainly consists of intelligent sensors, communication substations, communication interfaces, and monitoring computers. Essentially, the test system is an information system specially designed for mine shaft monitoring. It supports the monitoring of temperature, geotechnical pressure, water pressure and rebar stress and such functions as continued testing, computer analysis and security alerts. According to wellbore size and stratum features, four survey areas were arranged in major aquifers and interfaces with great stratum changes. Considering the anisotropy of the rock and soil, eight soil pressure test points were arranged at equal spacing along the circumference of the wellbore; four rebar stress test points and three pore water pressure test points were arranged at equal spacing on the outer wall of the wellbore; an additional rebar stress test points and three pore water pressure test points were arranged at equal spacing on the inner wall of the wellbore. The rebar sensors, pore water pressure sensors and soil pressure sensors are also capable of temperature measurement (Figure 1).
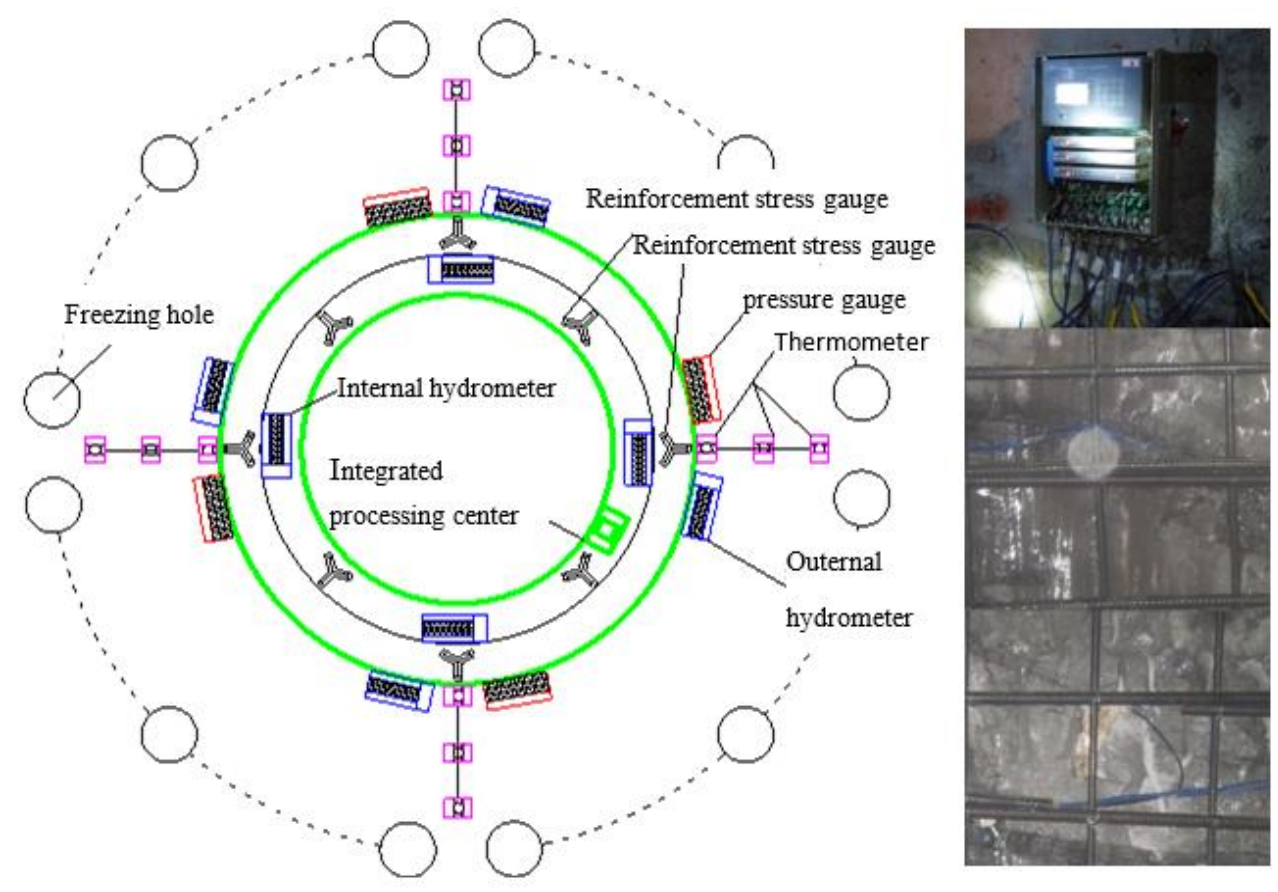

Figure 1. Sensor arrangement

\subsection{Temperature field change law}

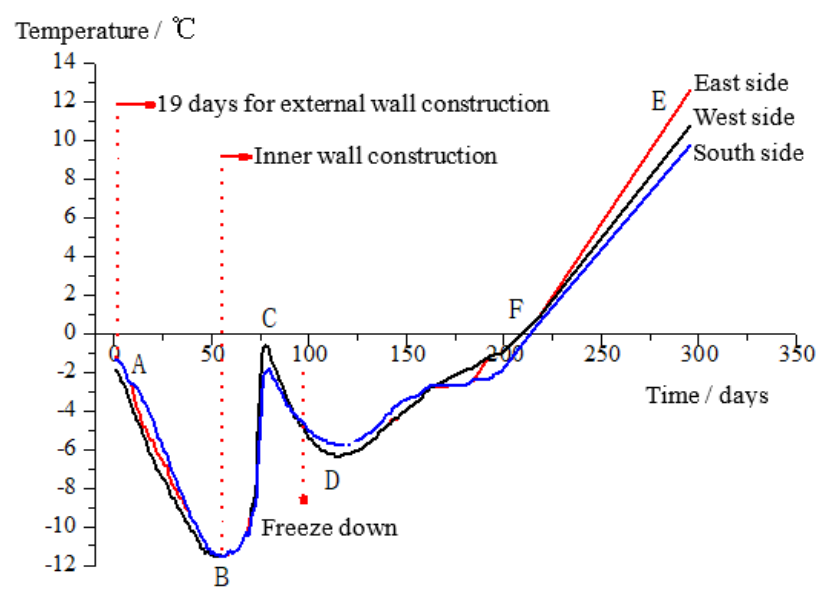

Figure 2. Temperature variation of typical measuring points

The instruments in each test section were installed before the construction of the outer wall of the wellbore. The data were collected $6 \sim 19$ days after the concrete pouring. The test system records the temperature variation of the side wall during the thawing and refreezing of the frozen soil after the construction of the outer wall, and that during the thawing, refreezing and unfreezing after the construction of the inner wall. Due to the destruction of the north side of the construction, only the southern side, the east side and the west side of the survey point data. Figure 2 displays the temperature variation law in a typical test section.

\section{SIMULATION AND ANALYSIS OF FREEZING SHAFT TEMPERATURE FIELD}

\subsection{Analysis of freezing shaft temperature field considering groundwater seepage}

The artificial freezing temperature field is an unstable temperature field with phase change and with internal heat source. When groundwater is flowing in the stratum, the temperature field control equation can be expressed as:

$$
\begin{aligned}
& C_{(T) n} \gamma_{(T) n} \frac{\partial T}{\partial t}=\frac{\partial}{\partial x}\left(\lambda_{(T) n} \frac{\partial T_{n}}{\partial x}\right)+ \\
& \frac{\partial}{\partial y}\left(\lambda_{(T) n} \frac{\partial T_{n}}{\partial y}\right)-c_{w} \gamma_{w}\left(V_{x} \frac{\partial T_{n}}{\partial x}+V_{y} \frac{\partial T_{n}}{\partial y}\right)
\end{aligned}
$$


$V_{x}^{n}=-K_{x(T)} \frac{\partial H}{\partial x} \quad V_{y}^{n}=-K_{y(T)} \frac{\partial H}{\partial y}$

$s_{n} \frac{\partial H_{n}}{\partial t}=\frac{\partial}{\partial x}\left(K_{(T)} \frac{\partial H_{n}}{\partial x}\right)+\frac{\partial}{\partial y}\left(K_{(T)} \frac{\partial H_{n}}{\partial y}\right)$

where $\mathrm{C}_{(T)}$ is the specific heat of the stratum $\left(\mathrm{m}^{2} /\left(\mathrm{s}^{2 \circ} \mathrm{C}\right)\right) ; \gamma_{(T)}$ is the bulk density of the stratum $\left(\mathrm{kg} / \mathrm{m}^{3}\right) ; \lambda_{(T)}$ is the thermal conductivity coefficient of the rock formation $\left(\mathrm{kgm} /\left(\mathrm{s}^{3 \circ} \mathrm{C}\right)\right) ; c_{w}$ is the specific heat of the groundwater $\left(\mathrm{m}^{2} /\left(\mathrm{s}^{2 \circ} \mathrm{C}\right)\right) ; \gamma_{w}$ is the bulk density of the groundwater $\left(\mathrm{kg} / \mathrm{m}^{3}\right) ; V_{x}$ and $V_{y}$ are the velocity components of seepage water $(\mathrm{m} / \mathrm{s}) ; \mathrm{K}_{(T)}$ is the permeability coefficient; $H$ is the head pressure $(\mathrm{Pa}) ; n$ is the state of frozen soil (the soil is not frozen if $n=1$ and frozen if $n=2)$.

For a specific problem, it is difficult to arrive at an analytical solution using equations (1) and (2). The most effective analysis method lies in the numerical method. Here, the FLAC $^{3 \mathrm{D}}$ programmable solution method is adopted for the numerical simulation of the effect of groundwater fluidity on the freezing shaft temperature field.

\subsection{Simulation and analysis of the distribution of freezing shaft temperature field}

The air shaft in the target coalmine uses a freezing plan of a single ring of freezing holes and auxiliary freezing holes. In the active freezing period, the brine temperature was $-28^{\circ} \mathrm{C} \sim$ $30^{\circ} \mathrm{C}$. In actual modelling, however, it is necessary to consider the stratum aquosity, groundwater fluidity, and freezing hole deflection. For convenience, the following simplifications were made during the modelling process:

(1) The effect of freezing hole deflection was neglected;
(2) The brine temperature source for ground temperature circulation of the freezing holes was simplified as a fixed temperature zone. The temperature of the freezing hole area was set to $-28^{\circ} \mathrm{C}$ according to the temperature of the brine circulation inlet and loop on the daily report on freezing. The numerical simulation model is presented in Figure 3 below.
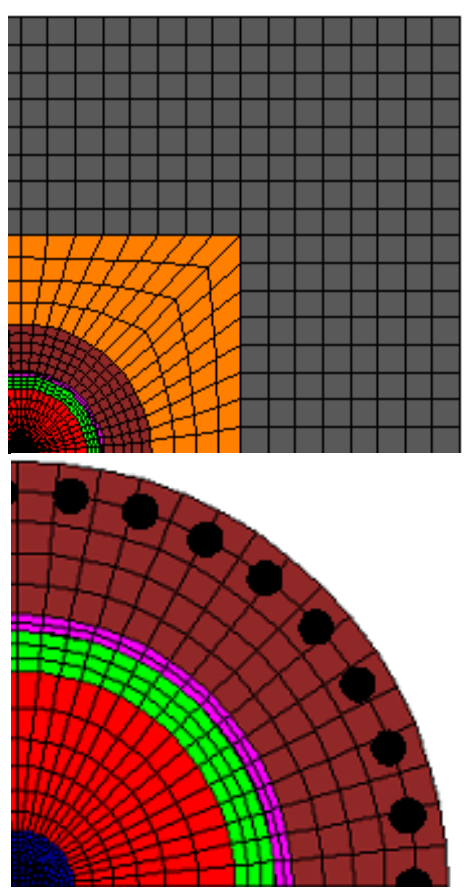

Figure 3. Temperature field numerical model

The thermal parameters of the stratum were determined through the optimization of the thermal parameters of the model according to the indoor test and onsite monitoring data (Table 1).

Table 1. Main parameters of the freezing design

\begin{tabular}{|c|c|c|c|c|c|c|}
\hline $\begin{array}{l}\text { Density } \\
\mathrm{kg} / \mathrm{m}^{3}\end{array}$ & $\begin{array}{c}\text { water } \\
\text { content \% } \\
\end{array}$ & $\begin{array}{l}\text { Phase transition } \\
\text { temperature }{ }^{\circ} \mathrm{C} \\
\end{array}$ & temperature ${ }^{\circ} \mathrm{C}$ & $\begin{array}{c}\text { Thermal conductivity } \\
\mathrm{W} / \mathrm{m} \cdot{ }^{\circ} \mathrm{C} \\
\end{array}$ & temperature ${ }^{\circ} \mathrm{C}$ & $\begin{array}{c}\text { Volume hot-melt } \\
\mathrm{kJ} / \mathrm{m} \cdot{ }^{\circ} \mathrm{C}\end{array}$ \\
\hline \multirow{6}{*}{26.2} & \multirow{6}{*}{21.6} & \multirow{6}{*}{-1.6} & $<15$ & 1.64 & $<15$ & 1.30 \\
\hline & & & $<0$ & 1.70 & $<0$ & 1.21 \\
\hline & & & $<-2$ & 1.76 & $<-2$ & 1.12 \\
\hline & & & $<-5$ & 1.81 & $<-5$ & 1.07 \\
\hline & & & $<-15$ & 1.86 & $<-15$ & 1.02 \\
\hline & & & $<-20$ & 1.91 & $<-20$ & 0.97 \\
\hline
\end{tabular}

The initial conditions include the distribution of ground temperature and the groundwater fluidity. According to the geothermal test data of the Binchang mining area, the distribution law of the geothermal depth can be expressed as:

$$
T=13.32+1.01 h / 100, h \geq 20.0 m
$$

The groundwater fluidity was determined in light of the experimental results of the aquifer flow rate (Table 2 ).

During the simulation, the initial ground temperature was set to $15.0^{\circ} \mathrm{C}$, the fixed temperature boundary was set to $15.0^{\circ} \mathrm{C}$ at the boundary of $r=60.0 \mathrm{~m}$, and the freezing tube temperature was controlled at $-28^{\circ} \mathrm{C} \sim-30^{\circ} \mathrm{C}$ during the active freezing phase. Considering the impact of freezing temperature on thermal parameters, the simulation was carried out in a saturated environment: coarse-grained sandstone aquifer. The variation in temperature field at different freezing times was observed according to the simulation results (Figure 4).

Table 2. Test results on aquifer flow rate

\begin{tabular}{|c|c|c|c|c|}
\hline Geologic Age & $\begin{array}{c}\text { depth } \\
\text { (m) }\end{array}$ & $\begin{array}{c}\text { Current } \\
\text { Speed }(\mathrm{m} / \mathrm{h})\end{array}$ & $\begin{array}{c}\text { Current } \\
\text { Speed }(\mathrm{m} / \mathrm{d})\end{array}$ & $\begin{array}{c}\text { Flow } \\
\left({ }^{\circ}\right)\end{array}$ \\
\hline \multirow{3}{*}{ The tertiary } & 15 & 0.454 & 9.571 & \multirow{3}{*}{274} \\
\hline & 25 & 0.574 & 13.185 & \\
\hline & 35 & 0.476 & 21.054 & \\
\hline \multirow{3}{*}{$\begin{array}{l}\text { Cretaceous } \\
\text { system }\end{array}$} & 145 & 0.871 & 20.154 & \multirow{3}{*}{181} \\
\hline & 200 & 0.875 & 21.597 & \\
\hline & 220 & 1.067 & 29.348 & \\
\hline
\end{tabular}




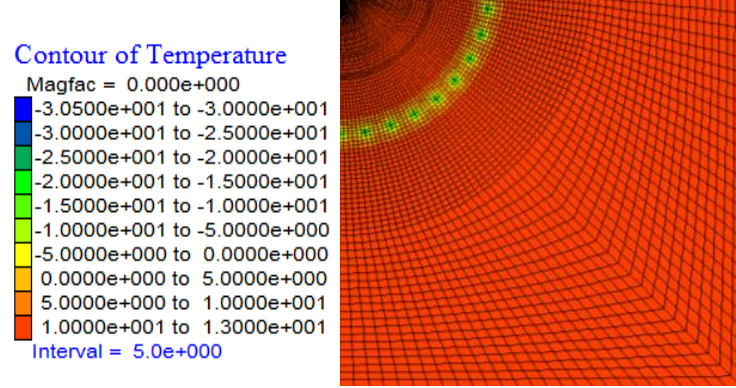

(a) $5 \mathrm{~d}$

Contour of Temperature Magfac $=0.000 e+000$

$-3.0500 e+001$ to $-3.0000 e+001$ $-3.0000 e+001$ to $-2.5000 e+001$ $-2.5000 e+001$ to $-2.0000 e+001$ $-2.0000 e+001$ to $-1.5000 e+001$ $-1.5000 \mathrm{e}+001$ to $-1.0000 \mathrm{e}+001$ $-1.0000 \mathrm{e}+001$ to $-5.0000 \mathrm{e}+000$ $-5.0000 e+000$ to $0.0000 e+000$ $0.0000 e+000$ to $5.0000 e+000$ $5.0000 e+000$ to $1.0000 e+001$ $1.0000+001$ to $1.30000+001$ terval $=5.0 \mathrm{e}+000$

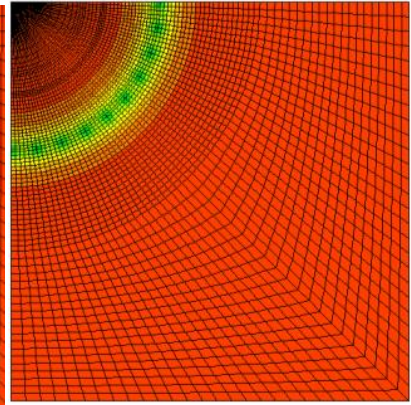

(b) $20 \mathrm{~d}$

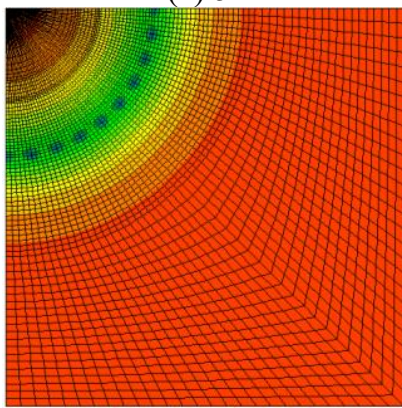

(a) $60 \mathrm{~d}$

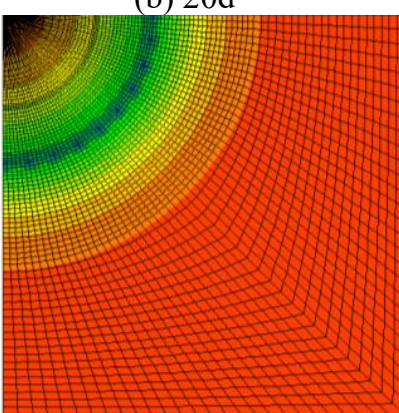

(b) $75 d$

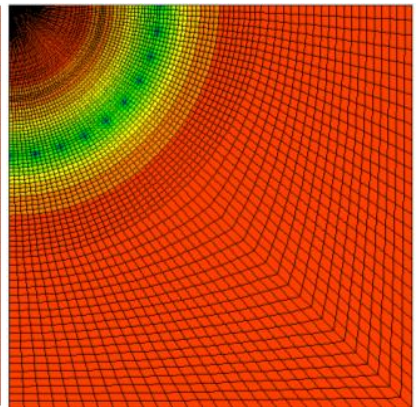

(c) $45 \mathrm{~d}$

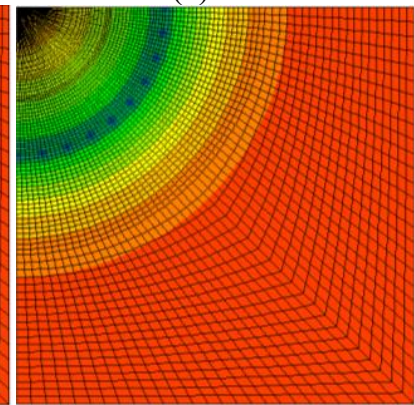

(c) $90 \mathrm{~d}$

Figure 4. Sandstone temperature field distribution

In view of the simulation results, the time-variation of the temperature at $r=0 \mathrm{~m}$ (the centre of the circle), $r=4.0 \mathrm{~m}$ and $r=9.0 \mathrm{~m}$ was determined (Figure 5).

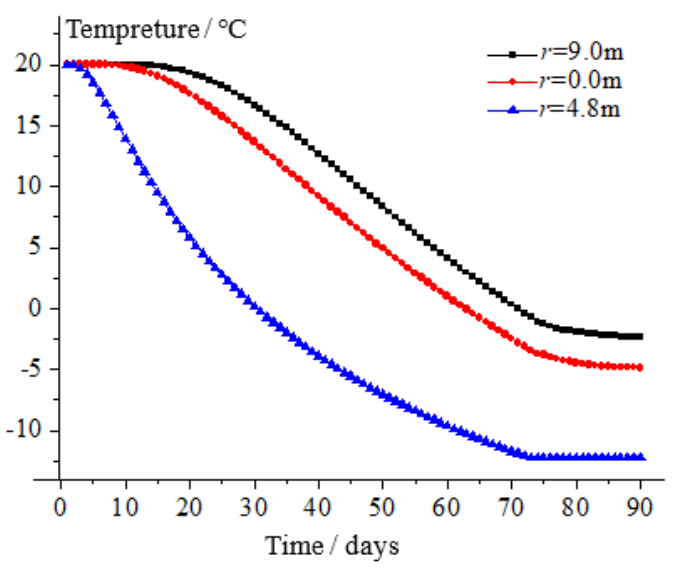

Figure 5. Temperature variation of typical measuring points

It can be seen from Figure 5 that the temperature of each measuring point decreased linearly with time, but the mean daily decline differed from point to point: the daily decline is negatively correlated to the distance from the freezing point, i.e. the temperature is positively correlated to the distance from the freezing point at the same time; on the two orthogonal radial monitoring lines, the measuring points at similar positions had basically the same temperature variation. This is because the groundwater flow rate and direction were changed during the numerical simulation.

\subsection{Effect of seepage on temperature field}

The flow of groundwater carries away most of the energy, which slows down the freezing of the wall and even prevents the closure. The hydrogeological data of the shaft shows that the flow rate of the groundwater in the aquifer peaks at $28.032 \mathrm{~m} / \mathrm{d}$. Using this value for simulation, it took $28 \mathrm{~d}$ for the frozen wall to realize closure. The frozen front developed at a mean rate of $0.116 \mathrm{~m} / \mathrm{d}$ and $0.065 \mathrm{~m} / \mathrm{d}$ before and after the closure. The development speed plunged after the closure, because the groundwater carried away part of the energy. Figure 6 displays the time-variation of temperature at the internal monitoring point $r=4.0 \mathrm{~m}$ and the external monitoring point $r=7.5 \mathrm{~m}$.

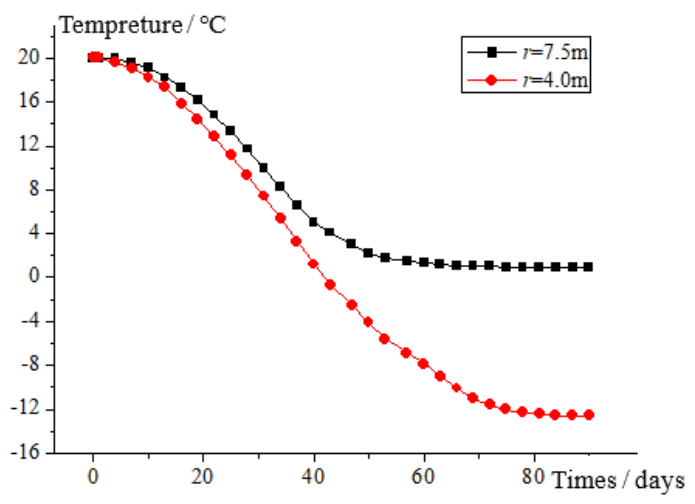

Figure 6. Temperature variation at the external and internal measuring points

As shown in Figure 6, the temperature dropped much faster at the internal monitoring point $(r=4.0 \mathrm{~m})$ than the external one $(r=4.0 \mathrm{~m})$. Besides, the peak temperature after freezing was gradually stabilized after $60 \mathrm{~d}$. To disclose the impact of groundwater flow rate on the development of the frozen wall, two simulation plans were prepared to calculate the variation in closure time and temperature at point $\mathrm{D}$, in which the groundwater flow rate was respectively $10 \mathrm{~m} / \mathrm{d}$ and $45 \mathrm{~m} / \mathrm{d}$.

Through simulation and analysis, it is learned that the freezing time for closure was $21 \mathrm{~d}$ at the groundwater flow rate of $5 \mathrm{~m} / \mathrm{d}$ and $79 \mathrm{~d}$ at $50 \mathrm{~m} / \mathrm{d}$. When the freezing intensity was weak (freezing tube temperature: $-22^{\circ} \mathrm{C}$ ), the frozen wall failed to achieve closure. The temperature variation of point $\mathrm{D}$ under the two working conditions is illustrated in Figure 7 below. 


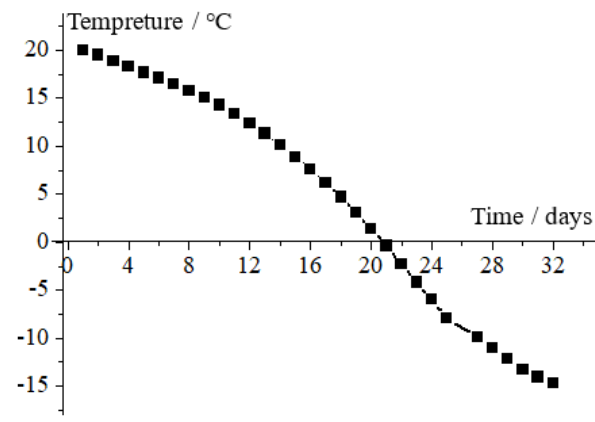

(a) Groundwater flow rate $5 \mathrm{~m} / \mathrm{d}$

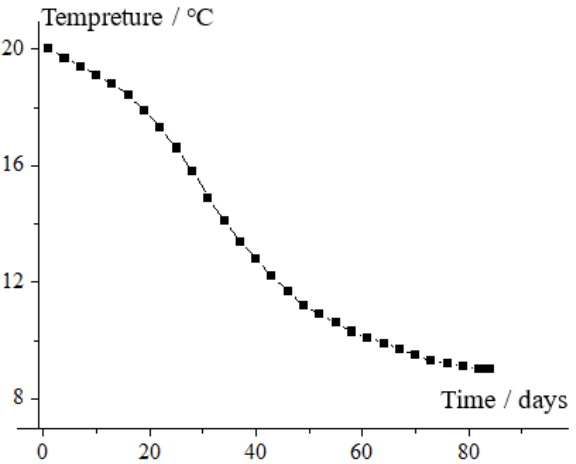

(b) Groundwater flow rate $50 \mathrm{~m} / \mathrm{d}$

Figure 7. Effect of groundwater fluidity on temperature change at point $\mathrm{D}$

It can be seen that, due to the fast flow rate of groundwater, the temperature at point $\mathrm{D}$ tended to be stable after dropping to $8.9^{\circ} \mathrm{C}$. The reason is that the heat flowing away from the groundwater is in equilibrium with the frozen heat. From the engineering point of view, the distance between the freezing pipes should be reduced for the faster underground water flow.

\subsection{Effect of freezing intensity on temperature field}

During the simulation and calculation, the freezing intensity was adjusted through the temperature control of the external wall of the freezing holes. The closure time of the frozen wall was calculated at the outer wall temperature of $-18^{\circ} \mathrm{C},-22^{\circ} \mathrm{C}$, $-26^{\circ} \mathrm{C}$ and $-30^{\circ} \mathrm{C}$, respectively. The groundwater flow rate was set to $-28 \mathrm{~m} / \mathrm{d}$. Under these conditions, the author computed the time it takes for the temperature at point $\mathrm{D}$ to drop to $-2^{\circ} \mathrm{C}$. The temperature variation at point $\mathrm{D}$ under the four working conditions is presented in Figure 8 below.

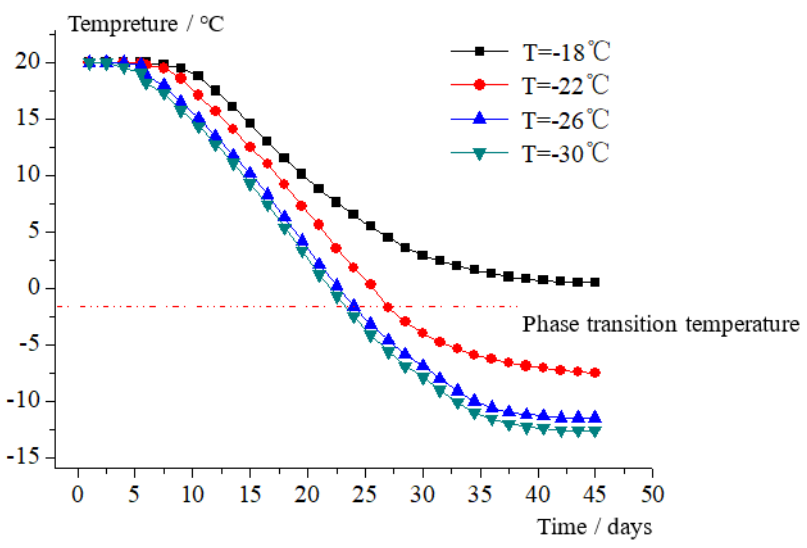

Figure 8 Temperature variation at point D under the four working conditions
According to the simulation results in Figure 8, the frozen wall failed to achieve closure under the low freezing intensity $\left(-18^{\circ} \mathrm{C}\right)$ due to the rapid flow of the groundwater. By contrast, the frozen wall developed quickly and achieved closure in a short time under the strong freezing intensity $\left(-26^{\circ} \mathrm{C}\right.$ and $30^{\circ} \mathrm{C}$ ). When the freezing intensity was $-22^{\circ} \mathrm{C}$, the temperature dropped slower than it did at $-26^{\circ} \mathrm{C}$ and $-30^{\circ} \mathrm{C}$, i.e. the frozen wall developed slowly. Due to loss of energy, the temperature of the measuring point must fall below that of the outer wall of the freezing tube. Taking the phase change temperature as the reference, the author determined the time to achieve closure under each of the four working conditions (Table 3 ).

Table 3. The time to achieve closure

\begin{tabular}{c|c|c|c|c}
\hline $\begin{array}{c}\text { Different } \\
\text { freezing } \\
\text { conditions }\end{array}$ & $\begin{array}{c}\text { Working } \\
\text { condition } \\
\text { one }\end{array}$ & $\begin{array}{c}\text { Working } \\
\text { condition } \\
\text { two }\end{array}$ & $\begin{array}{c}\text { Working } \\
\text { condition } \\
\text { three }\end{array}$ & $\begin{array}{c}\text { Working } \\
\text { condition } \\
\text { fure }\end{array}$ \\
\hline $\begin{array}{c}\text { Freezing } \\
\text { strength }\end{array}$ & $-18^{\circ} \mathrm{C}$ & $-22^{\circ} \mathrm{C}$ & $-26^{\circ} \mathrm{C}$ & $-30^{\circ} \mathrm{C}$ \\
\hline Lap time & $\begin{array}{c}\text { Unable to } \\
\text { turn in a } \\
\text { circle }\end{array}$ & 27 days & 21 days & 20 days \\
\hline
\end{tabular}

\section{CONCLUSIONS}

This paper creates a numerical model for the freeze sinking under seepage conditions, and explores the impacts of seepage and freezing intensity on the distribution of freezing temperature field. The main conclusions are as follows:

(1) The numerical model was verified through the comparison between the simulated data and the onsite monitored data. Then, the model parameters were adjusted. The model was proved as satisfactory according to the temperature change at key points.

(2) The temperature of each measuring point decreased linearly with time, but the mean daily decline differed from point to point: the daily decline is negatively correlated to the distance from the freezing point, i.e. the temperature is positively correlated to the distance from the freezing point at the same time.

(3) The freezing time for closure was $79 \mathrm{~d}$ at the groundwater flow rate of $50 \mathrm{~m} / \mathrm{d}$. When the freezing intensity was weak (freezing tube temperature: $-22^{\circ} \mathrm{C}$ ), the frozen wall failed to achieve closure. This means the groundwater directly bears on the distribution of the temperature field.

(4) The freezing intensity has a nonlinear impact on the temperature field. The higher the temperature, the smaller the impact on the closure.

\section{ACKNOWLEDGEMENTS}

This paper is made possible thanks to the generous support from National Natural Science Foundation of China (Grant No.: 51404193), General Project of China Postdoctoral Fund (Grant No.: 2015M572581), and Youth Talent Project of Shaanxi Provincial Natural Science Foundation (Grant No.: S2015YFJQ1194).

\section{REFERENCE}

[1] Hu XD, Fang T, Han YG. (2017). Generalized analytical 
solution for steady state temperature field of annular double loop tube freezing. Journal of Coal 42(9): $2287-$ 2294. https://doi.org/10.13225/j.cnki.jccs.2016.1628

[2] Hu XD, Han YG. (2015). General analytical solution to steady-state temperature field of single-circle-pipe freezing. Zhongnan Daxue Xuebao Journal of Central South University: Sciences \& Stechnology 46(6): 23422349. 7207.2015.06.047

[3] Li GF, Li N, Liu NF. (2017). A simplified three phase field coupling algorithm based on FLAC3D. Chinese Journal of Rock Mechanics and Engineering (a02): $3841-$ 3851.

[4] Shi RJ, Yue FT, Zhang Y. (2014). Distribution characteristics of temperature field in inclined shaft with liquidnitrogen reinforcement. Chinese Journal of Rock Mechanics and Engineering 33(3): 567-574.

[5] Chen JH, Li DW. Temperature field frozen with multicircle pipes in shaft sinking: feature analysis and engineering application. Journal of Glaciology and Geocryology $38(6)$ : $\quad 1568-1574$. https://doi.org/10.7522/j.issn.1000-0240.2016.0183

[6] Chen JH, Liu TY, Li DW. (2017). Study on artificial three - tube freezing model test and freeze program. Coal Science and Technology 45(12): 94-100.

[7] Yang GS, Qu YL, Xi JM, Li B. (2014). In-situ measurement and study of freezing pressure of shaft in western cretaceous water-rich bedrock. Journal of
Mining \& Safety Engineering 31(6): 982-987.

[8] Xiang Z. (2012). Obseration and analysis of the temperature field of host well tube frozen by stages. Journal of Glaciology and Geocryology 34(5): 11791183.

[9] Qing F. (2012). Cretaceous strata double lining structure optimization design. Anhui: AnHui University of Science and Technology.

[10] Ren JX, Sun JL, Zhang K. (2017). Mechanical properties and temperature field of inclined frozen wall in waterrich sand stratum. Rock and Soil Mechanics 38(5): 14051412. https://doi.org/10.16285/j.rsm.2017.05.023

[11] Sheng TB, Wei SY. (2012). Measurement and engineering application of temperature field multiplering hole frozen wall in extra-thick clay strata. Chinese Journal of Geotechnical Engineering 34(8): 1516-1521.

[12] Zhang S, Zhao T, Li F. (2018). Mechanical equipment vibration condition monitoring of holographic spectrum technology and shafting space vibration mode based on the microsoft visual studio.net environment. Chemical Engineering Transactions 66: 733-738. https://doi.org/10.3303/CET1866123

[13] Jusoh M, Mohamed NN, Yahya N, Musa R, Mohamad Z, Ngadi N, Rahman RA, Johari A, Zakaria ZY. (2018), Process optimisation of effective partition constant in coconut water via progressive freeze concentration. Chemical Engineering Transactions 63: 403-408, https://doi.org/10.3303/CET1863068 